\title{
Generalised Cost Function of Integrated Multimodal Transport
}

\author{
Paritosh Nandi ${ }^{1}$, Grzegorz Sierpiński ${ }^{2, *}$ \\ ${ }^{1}$ EnVERT Group \\ Kolkata, India \\ paritosh@envertgroup.com \\ ${ }^{2}$ Silesian University of Technology, Faculty of Transport and Aviation Engineering, Department of Transport Systems, \\ Traffic Engineering and Logistics \\ Krasińskiego Str. 8, 40-019 Katowice, POLAND \\ * Corresponding author: grzegorz.sierpinski@polsl.pl
}

\section{Extended Abstract}

To develop and implement Sustainable Urban Mobility Plans (SUMPs) [1] planners in the European Union (EU) usually apply participatory approaches involving interdisciplinary planning teams with transport planners, urban designers, environment experts, as well as decision-makers, urban transport and mobility practitioners, citizens and other stakeholders. To evaluate the effect of SUMPs, the EU sets measurement goals derived from local or national objectives and adopts routine monitoring and assessment activities. In line with this broad-based approach this paper will investigate the integration of multimodal transport system in the EU in particular. Building missing links at borders between the EU Member States and the main European routes, removing bottlenecks of network interconnections or the terminal modes are important to the European Single market [2]. Moving infrastructure to digital mobility patterns, and technology implementation for renewable fuels might impose additional burden in terms of new investment in multimodal network and its holistic integration. Heeres et al [3] established a conceptual structure for differentiating varying degrees in a 'solution space' method in the projects of transport integration. They thought that sector-internal integration is a multimodal one with connected nodes and interlinking of local and regional level networks. More cost-effective external integration explicitly extends the scope of improving connectivity to other interconnected transit networks and other parameters such as place of residence, leisure activities, and the environment.

This article also investigates the current renewable energy deployment pattern in Europe which needs an infrastructural change to tempt the private and public owners to deploy higher amount of renewable energy. Therefore the notion of multimodal integration is heavily dependent on the investment in infrastructure but the right kind of incentive to renewable energy will act in favour of the governmental goals and priorities. Particularly the Trans-European Transport Network (TEN-T) [4] needs new investment infrastructure, renovation and modernization of the already existing network. This article finally investigates the generalized cost functions and constraints of multimodal transport and travellers' choice taking into account the entire landscape of infrastructural changes required for the above-mentioned parameters and how this cost function plays out optimally across these factors.

\section{References}

[1] https://ec.europa.eu/transport/themes/urban/urban-mobility/urban-mobility-actions/sustainable-urban_en

[2] EIB Investment Report 2017/2018: From recovery to sustainable growth - Key Findings, 23 November 2017: http://www.eib.org/en/infocentre/publications/all/investmentreport-2017.htm. Infrastructure investment covers transport, communication, utilities, education and health.

[3] Heeres, N., Tillema, T., Arts, J., 2016. Dealing with interrelatedness and fragmentation in road infrastructure planning: an analysis of integrated approaches throughout the planning process in The Netherlands. Plan. Theory Pract. 17, 421-443

[4] https://ec.europa.eu/transport/themes/infrastructure/ten-t_en 